\title{
Review Sistem Rem ABS Pada Kendaraan
}

\author{
Baginda Pangidoan Tanjung \\ Mahasiswa Program Studi Mesin Otomotif, \\ Fakultas Teknik, Universirtas Muhammadiyah Magelang \\ Eamail: Bagindatanjung7@gmail.com
}

\section{Ringkasan}

Pengereman pada kendaraan merupakan permasalahan yang penting dalam pengoperasian kendaraan, hal in imenyangkut keamanan dan kenyamanan pengguna kendaraan. Olah karena itu, sistem rem ABS yang terkontrol secara otomatis dapat mencegah rem terkunci.

\section{Pendahuluan}

Mengutip dari berbagai sumber penyebab rem blong di kendaraan bisa bermacam-macam. Mulai dari minyak rem yang habis (untuk kendaraan penumpang) hingga kanvas dan piston rem yang rusak. Piston atau kanvas rusak atau aus karena faktor usia pakai. Untuk mencegahnya, sebenarnya bisa dilakukan pemeriksaaan berkala setelah kendaraan menempuh jarak $10.000 \mathrm{~km}$. Faktor lain penyebab rem blong adalah selang minyak rem yang tersumbat. Umumnya, mobil penumpang menggunakan sistem pengereman dengan tekanan fluida dari minyak rem. Oleh karen itu, kondisi minyak rem dan selang minyak yang berukuran kecil sangat penting diperhatikan. Sering membuka tutup tabung minyak rem bisa menyebabkan kotoran masuk ke tabung dan kotoran bisa menyumbat selang. Akibatnya, fungsi pengereman tidak berfungsi dengan baik. Penyebab lainnya adalah, sil, piston rem, dan master rem yang sudah aus. Ada beberapa penyebab selain faktor usia, yakni kualitas minyak rem yang sudah tidak bagus karena telah expired atau karena terkontaminasi akibat sering membuka tutup tabung minyak (Kasmono, 2019). 
Pengereman pada kendaraan merupakan permasalahan yang penting dalam pengoperasian kendaraan, hal in imenyangkut keamanan dan kenyamanan pengguna kendaraan. Pada kendaraan umum yang dipakai di Indonesia menggunakan sistem rem lock, dimana roda berhenti berputar atau mengurangi kecepatan putar roda untuk menghentikan kendaraan atau mengurangi kecepatan kendaraan, hal ini dilakukan dengan cara menginjak pedal rem dimana variabel gaya tekannya sesuai dengan kebutuhan pengereman. Sistem lock ini mempunyai kelemahan, yaitu jarak berhenti yang panjang karena koefisien adhesif antara roda dan jalan kearah longitudinal menjadi kecil sehingga gaya pengereman menjadi minim.

Bagaimana cara mengatasi rem manual agar tidak mengunci saat pengereman: yaitu dengan mengembangkan sistem pada rem manual dengan menggunakan Anti-lock Brake System (ABS) agar kendaraan dapat dikendalikan saat pengereman mendadak. Sistem yang terkontrol secara otomatis untuk mencegah rem terkunci yang menyebabkan roda tergelincir dan tidak tentu arahnya sehingga mobil tidak terkendali. ABS menggunakan skema yang berbeda tergantung pada jenis rem yang digunakan. ABS dapat dibedakan dengan jumlah saluran yaitu: berapa banyak katup yang dikendalikan secara individual dan jumlah sensor kecepatan.

\section{Komponen dan Cara Kerja}

- Sensor Kecepatan

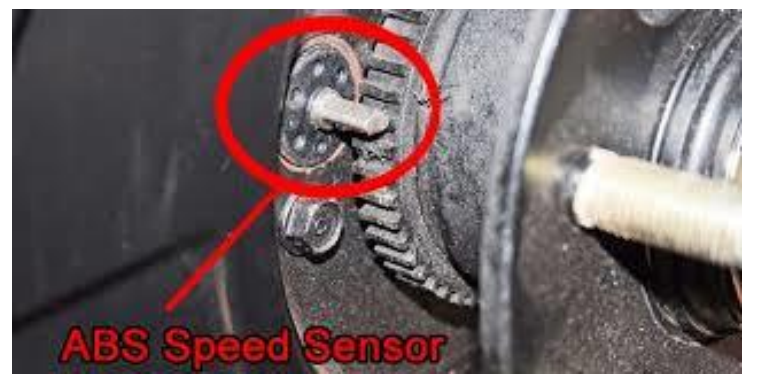

Gambar 1 Speed sensor

Sensor kecepatan pada pengereman ABS berguna untuk membaca kecepatan pada bagian putaran roda kendaraan, sensor ini akan dipasang pada setiap roda. 
- Katup Rem

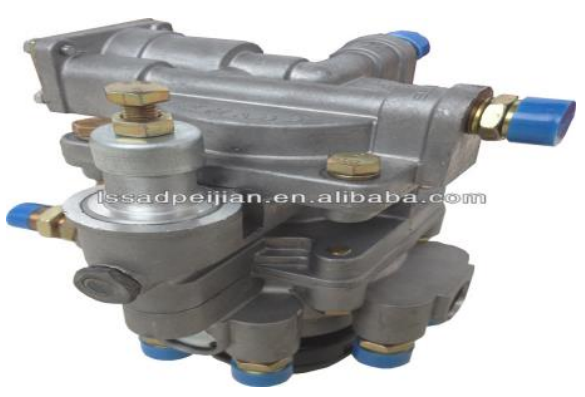

Gambar 2 katup pengereman $A B S$

Pada jalur minyak rem terdapat sebuah katup rem yang digunakan oleh kontroler ABS. Setidaknya ada 3 katup rem di ABS.

1) Katup posisi satu yang berada dalam posisi terbuka penuh, agar tekanan minyak rem bisa maksimal dan akan langsung disambungkan dengan rem.

2) Katup yang berfungsi menghalangi tekanan minyak rem, agar tekanan tidak bisa diteruskan ke rem.

3) Katup posisi tiga adalah katup yang berguna menghalangi beberapa tekanan minyak rem agar tekanan hanya setengah yang bisa dilanjutkan ke rem.

- Pompa (pump)

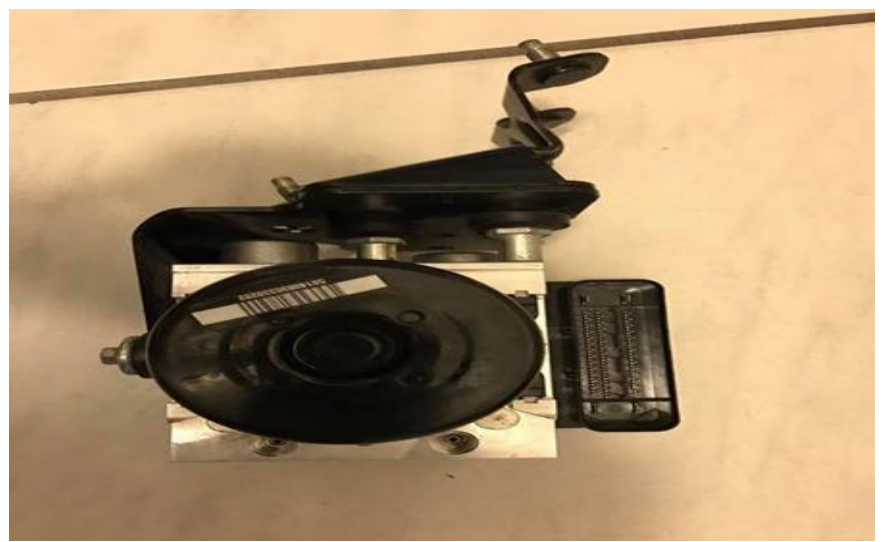

Gambar 3 ABS pump 
Pada rem ini juga memiliki sebuah pompa yang berfungsi untuk mengembalikan tekanan di jalur pengereman yang bisa diantarkan ke katup rem.

- ABS Control Unit

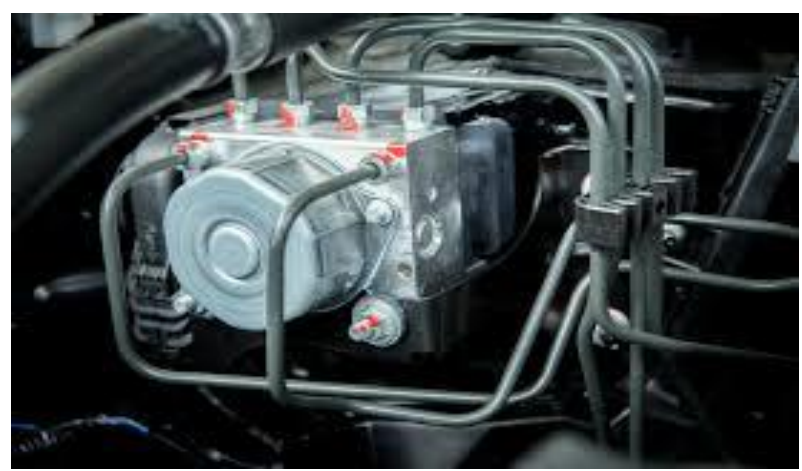

Gambar 4 ABS control unit

Kontroler pada sistem rem ini berfungsi untuk menjadi otak yang bisa mengendalikan komponen pada ABS dan mengolah datanya dari sensor kecepatan yang ada disemua bagian roda kendaraan.

- Sensor Putaran Akselerasi Belakang

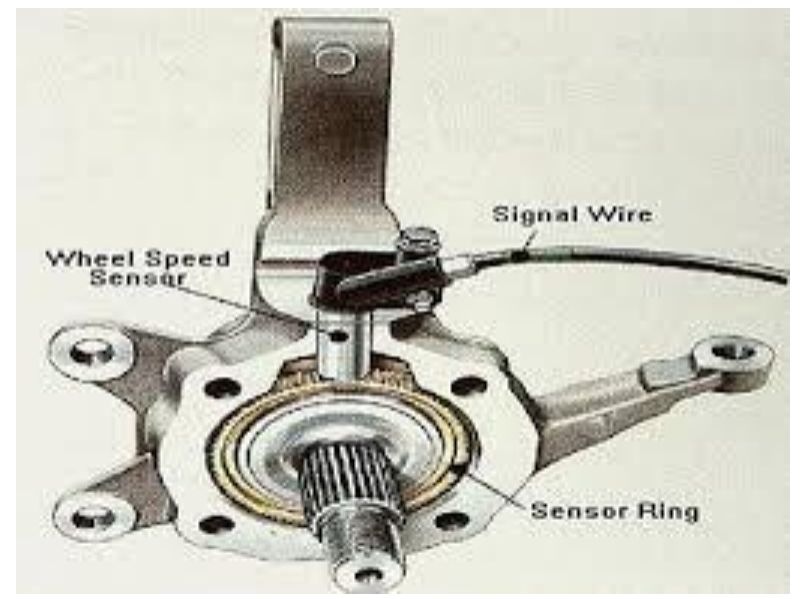

Gambar 5 Sensor putaran akselerasi belakang

Sensor putran aksel belakang berfungsi menghitung putaran roda secara induktif dan mengirim signal ke ABS control module. 
- Lampu Control

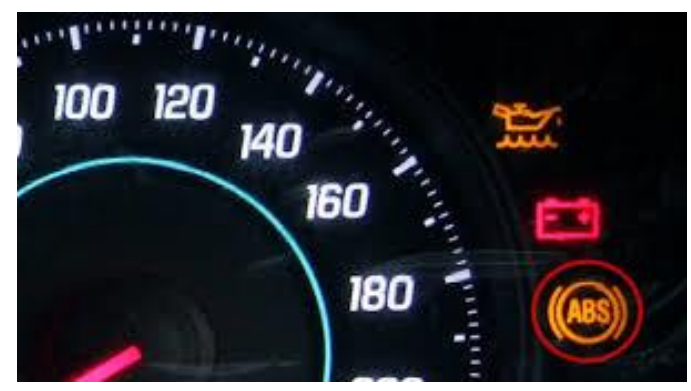

Gambar 6 Lampu control/indicator lamp

Lampu control berfungsi sebagai indicator ABS, bila terjadi kerusakan pada sisitem rem ABS. lampu indicator akan menyala.

- Unit Control Tekanan

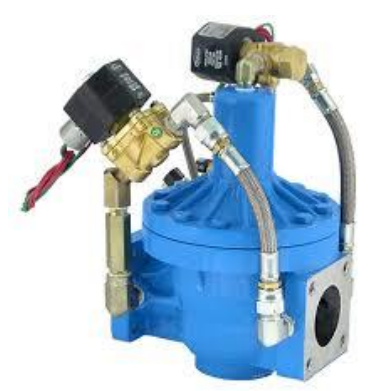

Gambar 7 unit control tekanan

Unit kontrol tekanan (akuator) berfungsi mengatur tekanan hidrolik rem untuk setiap roda sesuai dengan perintah computer.

\section{Perkembangan ABS}

ABS (Anti-lock Braking System) berguna untuk meminimalkan kemungkinan roda mengunci ketika melakukan pengereman keras. Dengan begitu mobil masih bisa diarahkan untuk manuver menghindar. Misalnya pada jalan raya yang lancer kemudian ada pemberhentian mendadak di lampu merah (Prasetyo et al., 2018). Sistem rem ABS ini terintegrasi dengan komputer. Ketika pengemudi menginjak penuh pedal rem, sensor kecepatan ABS di setiap roda akan membaca apakah ban mengunci atau tidak. Karena berfungsi untuk mencegah roda tidak terkunci, komputer akan mengatur tekanan hidraulis yang diterima oleh piston di kaliper rem. Itu sebabnya Anda akan merasakan tendangan balik pada pedal rem saat pengereman mendadak (panic brake) pada mobil ber-ABS. 
Dari kecepatan 50 km/jam di jalan kering, jarak pengereman hingga berhenti total yang dibutuhkan Vios adalah 9,6 meter dengan waktu 1,36 detik. Sementara jarak pengereman dari kecepatan $80 \mathrm{~km} / \mathrm{jam}$ memerlukan 26,7 meter dalam 2,18 detik (Nurohim et al., no date). Pada pengerema di jalan basah, Vios membutuhkan jarak 10,5 meter dengan 1,73 detik untuk berhenti total dari kecepatan $50 \mathrm{~km} / \mathrm{jam}$. Ini berarti lebih jauh 0,9 meter dari kondisi kering. Dengan kecepatan lebih tinggi yaitu $80 \mathrm{~km} / \mathrm{jam}$, Sedan ini membutuhkan jarak 28,48 meter dan waktu 2,44 detik, atau berselisih 1,78 meter dari kondisi kering. Hasil lainnya, sistem ABS membuat mobil tidak terindikasi membuang atau melintir baik di lintasan basah maupun kering (Al-Farouk Mitiqo, 2010)

\section{Kesimpulan}

ABS lebih efektif dibandingkan sistem rem konvensional, karena pada sistem ABS, semua sudah di kontrol oleh komputer sehingga kinerja rem menjadi lebi efektif dan mencegah terjadinya roda terkunci pada saat pengereman. Dengan ABS, pengemudi memungkinkan untuk mempertahankan kontrol pengendalian pada saat pengereman mendadak dan digunakan untuk memperpendek jarak pengereman dengan memperbolehkan pengemudi menginjak pedal rem secara penuh tanpa perlu khawatir kendaraan akan selip dan lepas kendali seperti pengereman pada kendaraan non ABS.

\section{Referensi}

Al-Farouk Mitiqo, P. (2010) No TitleRem ABS (Anti-Lock Braking Sistem), Ikhwafillah's Blog. Available at: https://panjimitiqo.wordpress.com/2010/05/22/rem-abs-anti-lock-braking-sistem/.

Kasmono (2019) Kasatlantas: Akibat rem blong terjadi kecelakaan lalu lintas beruntun, antara babel. Available at: https://babel.antaranews.com/berita/98101/kasatlantas-akibat-rem-blong-terjadikecelakaan-lalu-lintas-beruntun (Accessed: 1 August 2019).

Nurohim et al. (no date) 'Modification and Analysis of Trainer System of Car AntiLock Braking System (ABS)'.

Prasetyo, B. A. et al. (2018) 'Estimasi Pemborosan Bahan Bakar Akibat Kemacetan Menggunakan Analisis Citra Google Map (Studi Kasus pada Simpang Armada Town Square Mall Magelang)', Automotive Experiences. journal.ummgl.ac.id. 